\title{
Invasion of the noxious weed Nicotiana glauca R. Graham after an episodic flooding event in the arid zone of Australia
}

\author{
S.K. Florentine*, M.E. Westbrooke \\ School of Science \& Engineering, Centre for Environmental Management, \\ University of Ballarat, PO Box 663, Victoria 3350, Australia
}

Received 21 March 2003; received in revised form 23 February 2004; accepted 28 July 2004

\footnotetext{
*Corresponding author. Tel: +6135327 9231, Fax: +61353279240.

E mail address: s.florentine@ballarat.edu.au (S.K. Florentine).
} 


\section{Introduction}

Natural disturbances such as flooding and wind facilitate further extent of already established exotic species into new areas (Cellot et al., 1998; Williams and West, 2000; Varnjic et al., 2000). Virtue et al. (2001) suggested exotic species can invade into a new territory by several ways: incidental introduction by human influenced means, deliberate introduction, accidental movement, wind, water, and wild terrestrial vertebrates. Sometimes, native plant species rely on such events for their recruitment, growth and reproductive. In particular, in arid landscapes, high rainfall driven flooding events may occur only once in hundred years. These sporadic and unpredictable flooding events facilitate irruption of larger numbers of native annual and perennial species from the soil seed bank (Westbrooke et al., submitted). However, invasive taxa make use of such rare events to extend their territory. One such event occurred in Olary Creek in February 1997, after $216 \mathrm{~mm}$ of rainfall was received in $24 \mathrm{~h}$ in the Olary Ranges, South Australia. This high rainfall created a heavy flood and formed a terminal lake in Nagaela station, New South Wales. Although some studies have been carried out on high rainfall flooding events and their impacts on native species (Weston and Westbrooke, 1999; Florentine et al., 2003; Westbrooke et al., submitted), no work has been done on the impact of rare flooding event and exotic invasion of arid landscape in Australia.

Nicotiana glauca, a fast growing shrub or small tree, native to South America, belongs to the family Solanaceae (Mizrachi et al., 2000). It branches profusely, and can grow vigorously to $3 \mathrm{~m}$, particularly after good rainfall events. Flowering commences approximately one year after germination and a fully-grown plant can produce 10,000-1,000,000 seeds. The most effective mode of long-distance seed dispersal is through hydrochory. N. glauca is found in open and disturbed areas including wastelands, roadsides and creek lines (Boyland et al., 1985). Extensive stands may be found for some years on stream floodplains and drainage channels after summer floods (Cunningham et al., 1981). Studies have demonstrated that $N$. glauca is highly toxic to humans (Mizrachi et al., 2000) and animals (Panter et al., 2000). The species is usually avoided, as it is unpalatable; however during drought, when food resources are scarce, livestock may consume the plant and die (Cunningham et al., 1981). The plant contains the alkaloid anabasine, which is considerably more toxic than nicotine (Sims et al., 1999). Panter et al. (2000) found that $N$. glauca causes defects in foetal goats and sheep if the mother does not die from consumption of the plant.

Although a number of studies have been carried out on the toxicity of this plant in America and Germany, little research has been conducted in Australia. Extensive 
growth of $N$. glauca was observed around a lake, formed following a rare flood event in Olary Creek in 1997. The main objectives of this study were to investigate: (i) the distribution of $N$. glauca in relation to the 1997 flood event; (ii) the variation in $N$. glauca soil-stored seed densities between soil in control and exclosure plots and (iii) the allelopathic potential of $N$. glauca litter on germination of Lactuca sativa seeds.

\section{Materials and methods}

\subsection{Study area}

The study was conducted on Nagaela Station, around a lake formed in 1997 following a flood of Olary Creek. The ephemeral Olary Creek arises near Olary in the north east of South Australia. The creek flows south and east through South Australia to Oakvale Station. There it splits into two channels, one of which flows due east into New South Wales to fill Woolcunda Lake and White Lake, and the other south-east through Loch Lilly Station. The Creek flowed for the first time for many years in February 1989 and again, more extensively, in February 1997 following high rains in the catchment (Weston and Westbrooke, 1999). Following this event the southern arm flowed on into Nagaela Station where it formed a new lake of approximately 40 ha within mallee shrubland (Fig. 1). The lake gradually dried over a two-year period. Weston and Westbrooke (1999) indicate that the creek flowed only four times between 1921 and 1997. The flood in 1997 was the most extensive on record and followed a path to fill a lake not flooded since settlement. Preliminary studies at the site have helped to explain previously observed examples of perennial vegetation regeneration difficult to attribute to on-site rainfall events. The creek provides a model for many other such ephemeral creek systems across arid Australia.

\subsection{Chronological events}

Rare flooding event occurred in September 1997. Twenty months after flooding in November 1999 plots were established in the flooded and unflooded (control) area as the lake dried. One of the plots in the pair was left unfenced while the other was fenced to prevent grazing by vertebrate animals. Detailed vegetation data were collected in October 2000 (3 years and 10 months after the flooding event started) and October 2002 (5 years and 10 months after flooding event started).

\subsection{Distribution of $N$. glauca in relation to 1997 flooding event}

To assess the effects of the 1997 flood on native flora, six $25 \times 25 \mathrm{~m}^{2}$, exclusion plots were established on flooded (4) and non-flooded control (2) areas. Adjacent to each plot (fenced to exclude rabbits, goats and kangaroos), a control plot (located in close proximity to treatments plots, in the same ecological vegetation class and land systems) was also established by marking four corners with wooden stakes. The fence 


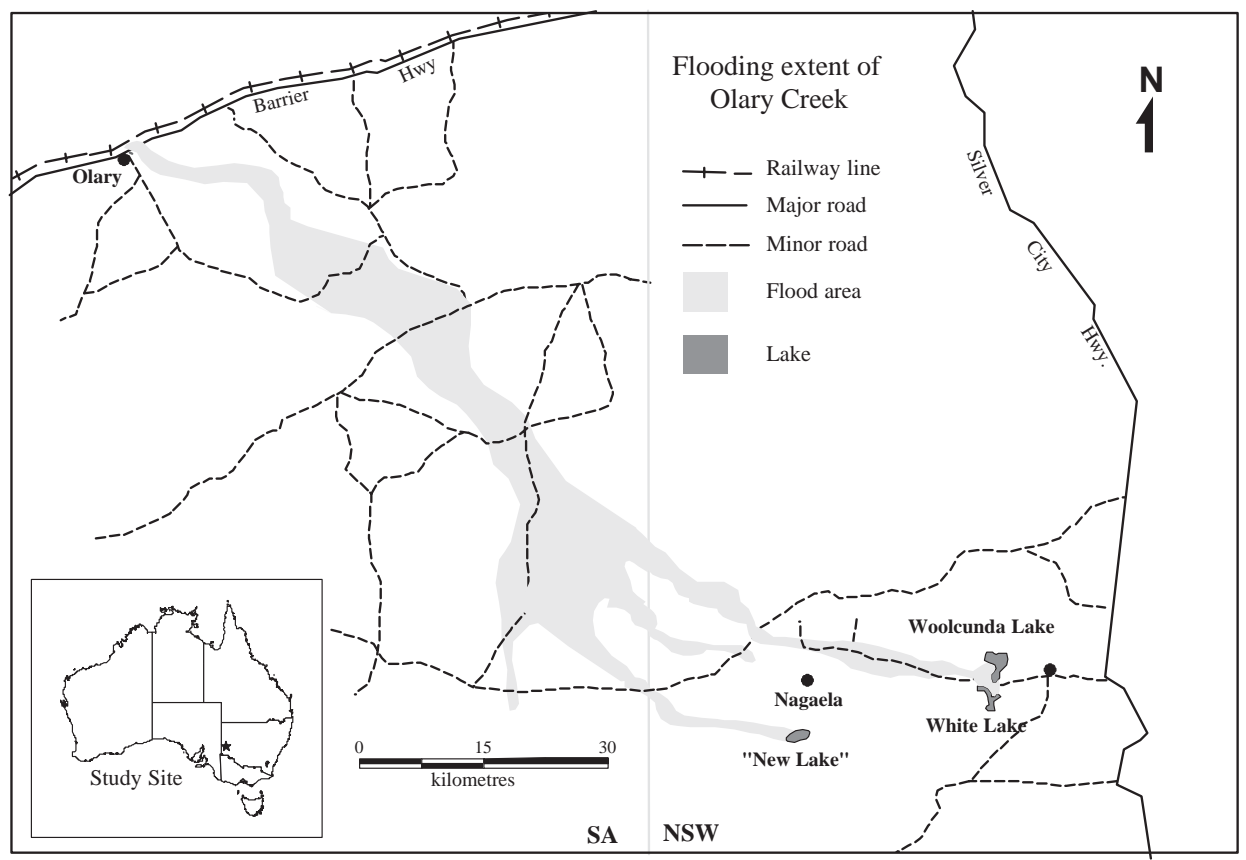

Fig. 1. Location of study site and extent of the 1997 Olary Creek flooding.

was $1.7 \mathrm{~m}$ tall, with a $150 \mathrm{~mm}$ mesh size and rabbit proof mesh to $80 \mathrm{~mm}$. The data presented here focuses on the response of $N$. glauca to the flood event. Plots were assessed in September 1998, October 2000 and October 2002. Each $25 \times 25 \mathrm{~m}^{2}$ plot was divided into $25,5 \times 5 \mathrm{~m}^{2}$ sub plots. Within each sub plot, all $N$. glauca species were located, their heights, diameter $(20 \mathrm{~cm}$ from the soil surface), and whether the plants were dead or had resprouted was recorded.

\subsection{Density distribution from the lake boundary}

Cunningham et al. (1981) reported that $N$. glauca grows on floodplains and drainage channels and is less prevalent away from creek lines. To examine the pattern of $N$. glauca distribution around the "new lake", belt transects $(294 \times 3$ and $228 \times 3 \mathrm{~m}^{2}$ ) were established running north and south from the lake centre. These belt transects were divided into three zones: long-term flood zone (approximately $1-1.5 \mathrm{~m}$ in depth flood water stayed approximately 20 months), short-term flood zone (approximately $30-50 \mathrm{~cm}$ depth floodwater stayed less than a year) and nonflood zone (just after the short term flood zone but far away from the control plots), based on the flooding mark. Each transect was divided further in to $3 \times 3 \mathrm{~m}^{2}$ subplots. Within each sub-plot the height $(\mathrm{m})$ and diameter $(\mathrm{cm})$ at $20 \mathrm{~cm}$ for all N. glauca were recorded. $N$. glauca used the 1997 rare flooding event to establish and 
survive, but during subsequent years of new average rainfall, $N$. glauca shed leaves and shoot tips dried out. However, during 2002 measurements, significant number of $N$. glauca plants started to resprout. Resprouting from the branch or base (close to root collar) or from both branches and base were recorded.

\subsection{Dendrochronology}

To link the 1997-flooding event with $N$. glauca recruitment five single stem trees of largest stem diameter were marked. These trees were cut down and sections cut approximately $1 \mathrm{~m}$ from the base. Sections were mounted and fine-sanded. Growth rings were counted on each sample under an Olympus ${ }^{\mathrm{TM}}$ (Model SZ-PT Sz40) compound microscope following the technique used by Hughes (1992). The dendrochronology study described incorporates two assumptions. Firstly, N. glauca produce one growth ring/year, secondly, sufficient samples are taken to cover local variation. Westbrooke (1999) confirmed annual growth ring in Myoporum platycarpum ssp. platycarpum growing in the same area.

\subsection{Soil-stored seed bank}

Soil samples were collected in October 2002. Twenty samples were collected from randomly selected points from each control and exclosure plot. Random $10 \times 10 \mathrm{~cm}^{2}$ quadrats were selected and soil was removed with a small trowel to a depth of $15 \mathrm{~cm}$. Samples were placed in separate labelled bags, transported to Ballarat and stored in a glasshouse $\left(20-25^{\circ} \mathrm{C}\right)$ for two days.

Individual samples were thoroughly mixed within the bag to ensure a uniform distribution between seeds and soil then spread evenly in $8.5 \times 14.0 \times 5.5 \mathrm{~cm}$ punnets lined with paper towel. Punnets were individually labelled with the sample number and placed in large trays $(28.0 \times 44.0 \times 5.5 \mathrm{~cm})$, which were placed on benches in a glasshouse. On each bench, a further tray containing sterilized soil placed randomly between soil seed sample trays was used as a control. All trays were watered twice a day. The germinable seed bank was considered as the number of seeds that germinated under favourable water and temperature conditions within 90 days (Bertiller, 1996). This measure provides an estimate of the immediately germinable seed bank. The number of germinated $N$. glauca seedlings was recorded weekly.

\subsection{Allelopathic effects}

An aqueous leachate of freshly collected $N$. glauca leaves, dry leaves, fresh bark and twigs $(>1 \mathrm{~cm}$ ) was prepared by soaking $30 \mathrm{~g}$ of material in $240 \mathrm{~mL}$ of deionized water (1:8 by weight) in $500 \mathrm{~mL}$ flasks for $24 \mathrm{~h}$ at room temperature. The leachate was filtered into a labelled flask, using Whatman ${ }^{\circledR}$ filter paper $(125 \mathrm{~mm}$, No: 3) and stored at $5{ }^{\circ} \mathrm{C}$ until use. Following filtering, four concentrations were prepared: Treatment 1 (control) $=100 \%$ deionized water; Treatment $2=100 \%$ leachate, Treatment $3=75 \%$ leachate $+25 \%$ deionized water, Treatment $4=50 \%$ 
leachate $+50 \%$ deionized water and Treatment 5=25\% leachate $+75 \%$ deionized water.

Seeds of L. sativa L. cv. Great Lakes were selected to test the effects of leachate on germination, because of their uniform germination behaviour (Dietz and Winterhalter, 1996) and sensitivity to germination inhibitors (Evenari and Newman, 1952). Four replicates, each of 50 seeds, were placed in labelled Petri dishes lined with two No. 3 Whatman ${ }^{\circledR}$ filter papers. The filter paper was moistened with $5 \mathrm{~mL}$ of aqueous leachates of the respective solutions, while the control received the same amount of deionized water. Petri dishes were placed in a growth cabinet at $21^{\circ} \mathrm{C}$ and kept moist until the experiment was terminated at 30 days.

\subsection{Data analysis}

Data were analysed using the Super ANOVA software program (Abacus Concepts, Berkeley, California) for obtaining two-way ANOVA and all pairwise multiple comparison procedures. Residual plots of each ANOVA were obtained to examine homogeneity of the variance. Data were then transformed log (stem diameter and height) or arcsign (L. sativa seed germination data) and reanalysed. Means were compared using Tukey's HSD test (Day and Quinn, 1989).

\section{Results}

\subsection{N. glauca seedling emergence in relation to flooding event}

N. glauca density varied between flooded fenced and unfenced plots and also varied between assessments. In September 1998, no N. glauca was found across flooded and control plots. In October 2000, densities of 24 and $12 \mathrm{~N}$. glauca seedlings $\mathrm{ha}^{-1}$ were recorded from flooded unfenced and fenced plots respectively. This number had significantly $(p>0.0001)$ increased by October 2002, when 756 and $468 \mathrm{ha}^{-1}$ were recorded in the flooded unfenced and fenced plots respectively. N. glauca was not recorded from control fenced and unfenced plots (Fig. 2).

During 2002 measurement the flooded unfenced plots $80 \%$ of the plants were found resprouted, and of these, $90 \%$ and $10 \%$ of them were resprouted from the base and from branches respectively. Only 20\% were found dead or not resprouted. Similarly in the flooded fenced plots $72 \%$ of plants resprouted, of these $87 \%$ and $13 \%$ resprouted from the base and branches respectively. Of 117 plants recorded $26 \%$ were either dead or not resprouted.

\subsection{Dendrochronology}

The dendrochronology study revealed a maximum of five growth rings. The dendrochronology study described incorporates two assumptions. Firstly, N. glauca produce one growth ring/ year, secondly, sufficient samples are taken to cover local 
variation. Westbrooke (1999) confirmed annual growth ring in Myoporum platycarpum ssp. platycarpum growing in the same area.

\subsection{Density distribution around the new lake}

There was a clear pattern in $N$. glauca distribution. In the two transects a total of 366 trees were recorded. Larger numbers of trees $(n=283)$ were recorded in the short-term flood zone followed by long-term flood zone $(n=53)$ and non-flood zone $(n=8)$ (Fig. 3A and B). A correlation analysis between diameter $(\mathrm{cm})$ and height $(\mathrm{m})$

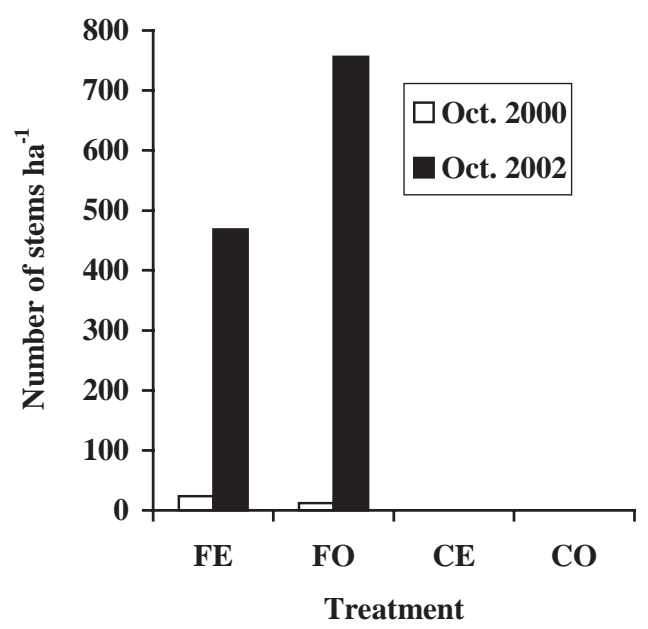

Fig. 2. N. glauca stem density in FE flood exclosure, FO flood open; CE control exclosure and $\mathrm{CO}$ control open.

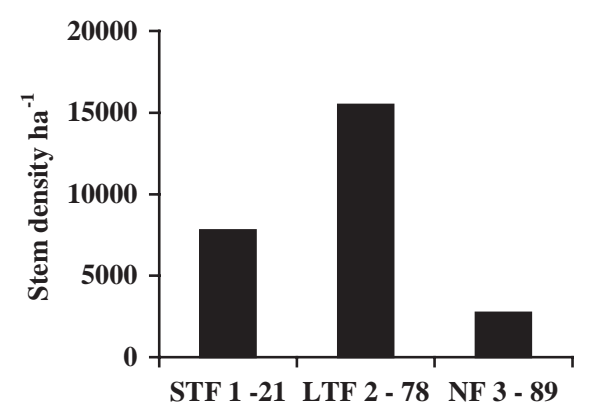

(A) Distance from the creek boundary

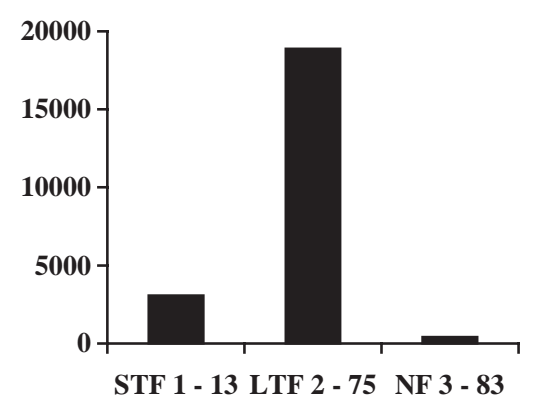

(B) Distance from the creek boundary

Fig. 3. N. glauca stem density distribution in relation to 1997 flood. Transect A, N S direction and B, S N direction. STF short term flood zone; LTF long term flood zone \& NF no flood. 
of $N$. glauca performed separately for both transects produced the following equations, for the two transects (Fig. 4A and B).

Transect 1 Height $=1.105+0.1142\left(R^{2}=0.85 ; p<0.0001\right)$,

Transect 2 Height $=0.977+0.1794\left(R^{2}=0.73 ; p<0.001\right)$.

A comparison of the $R^{2}$ values for Eqs. (1) and (2) indicated no difference between transects.

Similarly correlation analysis between stem diameter $(\mathrm{cm})$ and height $(\mathrm{m})$ of $N$. glauca was performed on the data collected from the flooded open and enclosed plots (Fig. 5A and B). The following equations were produced.

Open plots Height $=0.508+0.4368\left(R^{2}=0.29 ; p<0.005\right)$,

Enclosed plots $\mathrm{Height}=0.757+0.0230\left(R^{2}=0.35 ; p<0.003\right)$.

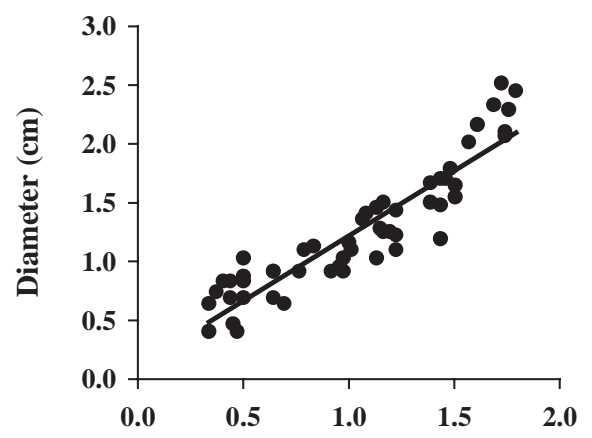

(A)

Height (m)

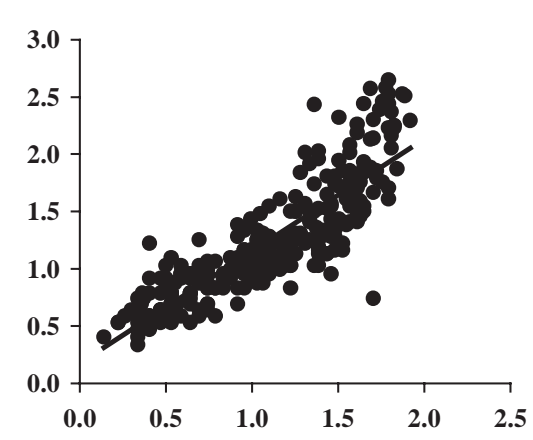

(B)

Height (m)

Fig. 4. The relationship between $N$. glauca height (m) and diameter (cm) measured in zone 1 (A) and 2 (B).

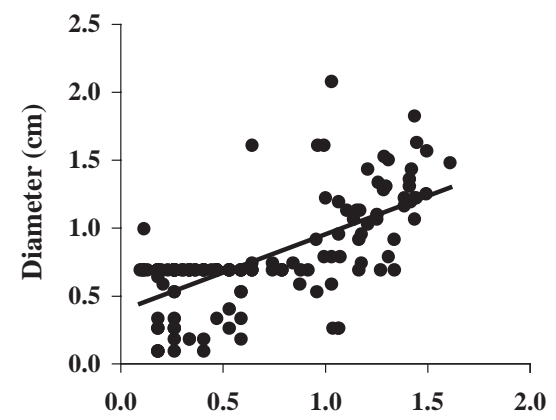

(A)

Height (m)

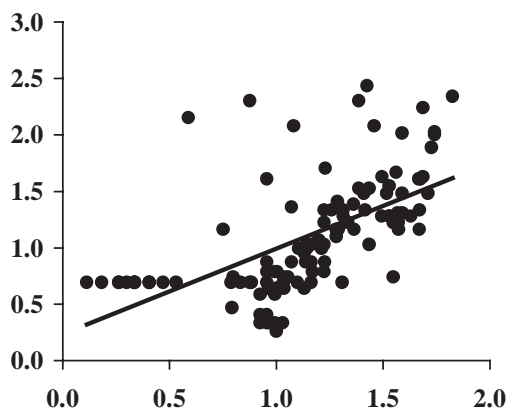

(B)

Height (m)

Fig. 5. The relationship between $N$. glauca height $(\mathrm{m})$ and diameter $(\mathrm{cm})$ measured in flooded open (A) and enclosed plots (B). 


\subsection{Resprouting}

In the long-term flood zone, $41 \%$ of trees had retained original growth. Of the remainder, which had died back; $57 \%$ and $5 \%$ of the trees resprouted from the base and branches respectively. In the short-term flood zone, $60 \%$ of trees had retained their original growth. Of the remainder 19\% had resprouted from the base, $13 \%$ from the stems and 7\% from the base and branches.

\subsection{Height and diameter class distribution}

The diameter class distribution pattern of $N$. glauca in both the long and shortterm flood zone showed an inverted 'J'curve. The vigour, as measured by height and diameter class distribution of $N$. glauca, varied between zones. In the long-term flood zone there was an even distribution of height classes. By contrast, in the short-term flood zone height class reduced slowly towards smaller diameter size class. It was difficult to establish a height class distribution pattern of $N$. glauca in the flood zone (Fig. 6A and B).

\subsection{Soil-seed bank}

Soil-stored seed bank density varied significantly $(p>0.0001)$ between flooded exclosed $(856 \pm 428.12)$ and flooded open $(1936 \pm 968)$ plots. No $N$. glauca seed was found in the control plots, confirming results for the tree density assessment (Fig. 7). Analysis of the interrelations between number of $N$. glauca stems found at the time of sampling and number of seeds (Fig. 8) recovered from the soil produced the equation:

Number of stems $=0.4036+24.935\left(R^{2}=0.97 ; p<0.001\right)$.
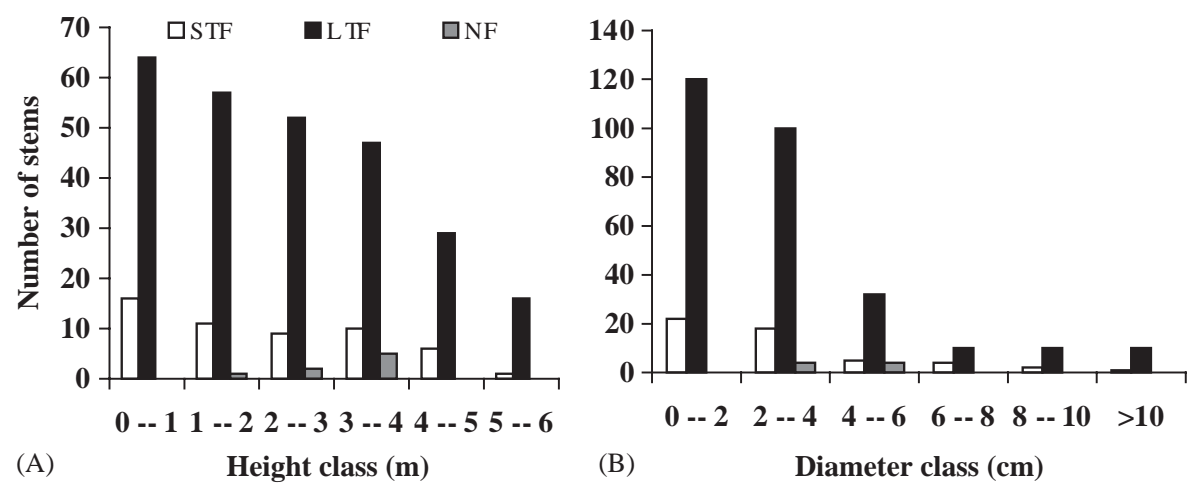

Fig. 6. Height (A) and diameter (cm) (B) distribution of $N$. glauca found in the Olary Creek. SFT short term flood zone; LTF long term flood zone and NF no flood. 


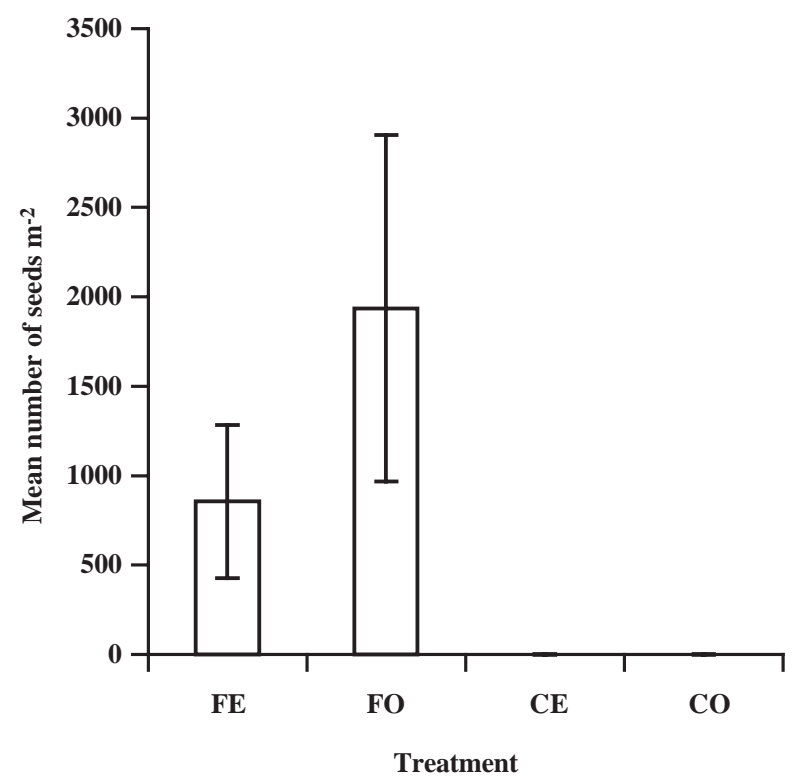

Fig. 7. N. glauca mean number of germinable seeds: FE flood exclosure, FO flood open; CE control exclosure and $\mathrm{CO}$ control open.

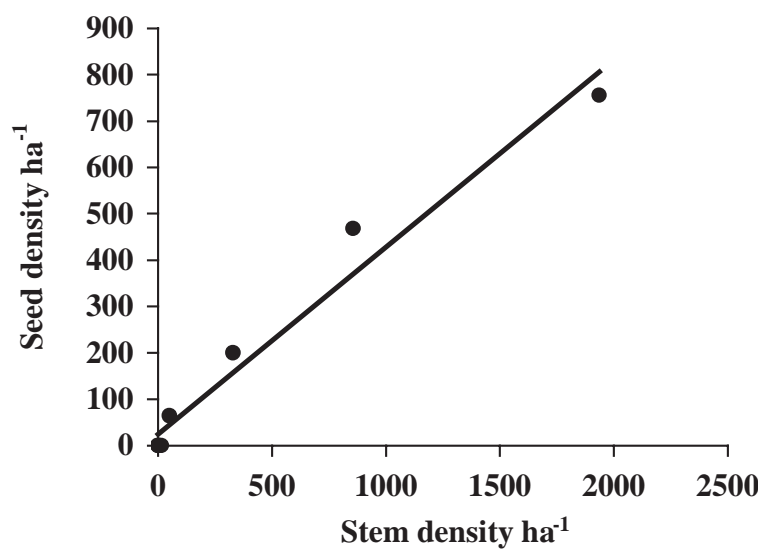

Fig. 8. The relationship between $N$. glauca stem density ha ${ }^{1}$ and seed density ${ }^{1}$.

\subsection{Allelopathic effect}

Leachates from dry leaves and twigs significantly $(p>0.001)$ decreased germination of $L$. sativa seeds. The effect was most pronounced with solutions of dry 
leaf extract where in treatment $2,3,4$, and 5 only $0,0.28,1.49$ and $2.86 \%$ seeds germinated respectively, compared to $99 \%$ in the control. Similarly the twig extract gave a progressively greater effect as concentration was increased. In contrast, fresh leaves and bark caused no inhibition of $L$. sativa seed germination (Fig. 9).

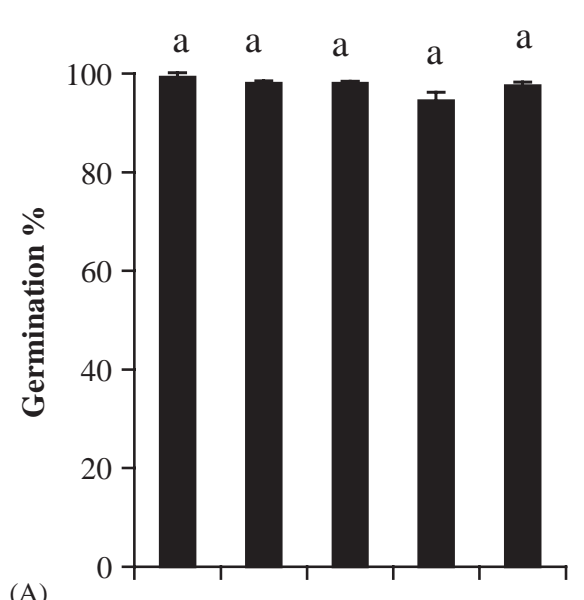

(A)

a

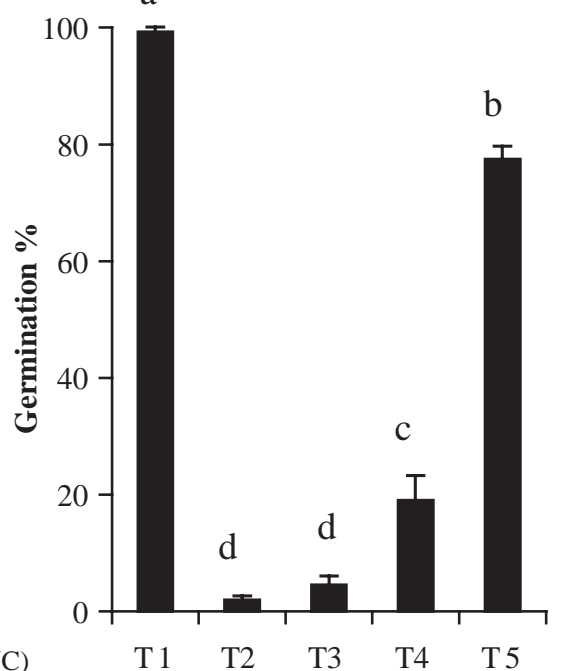

(B)
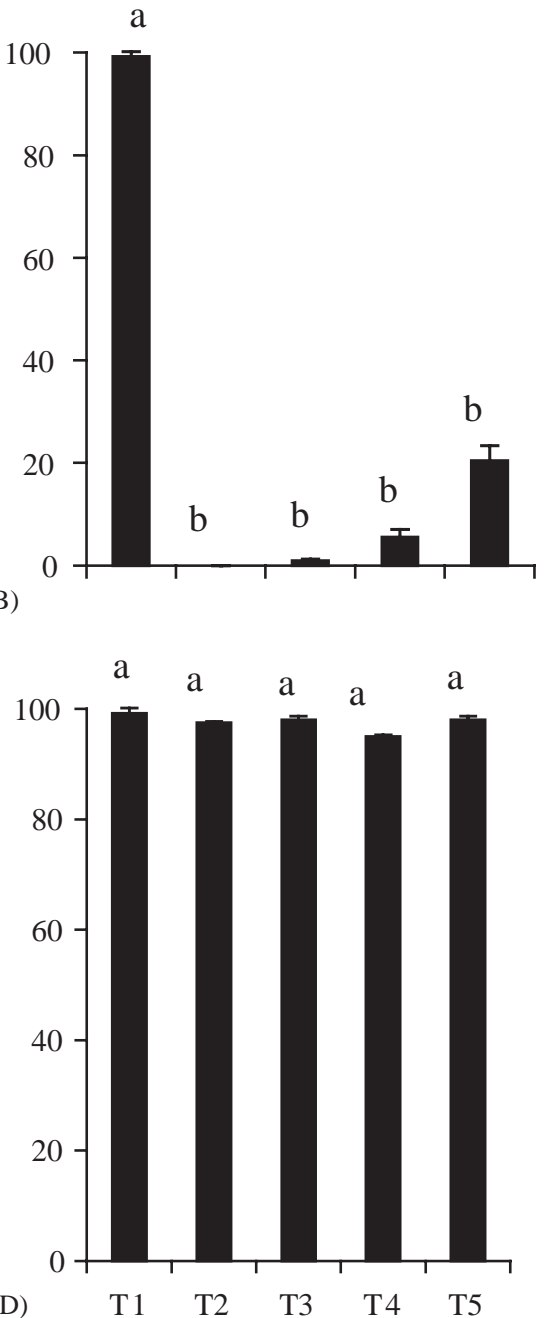

Fig. 9. L. sativa seed germination subject to $N$. glauca leachate. A green leaves leachate; B dry leaves leachate; C twig leachate, and D bark leachate. Treatment 1 (control) deionized water; Treatment $2100 \%$ leachate; Treatment $375 \%$ leachate $+25 \%$ deionized water; Treatment $4 \quad 50 \%$ lea chate $+50 \%$ deionized water and Treatment $5 \quad 25 \%$ leachate $+75 \%$ deionized water. Columns topped by the same letter are not significantly different $(p<0.05)$ as determined by Tukey's pairwise comparison. Vertical bars indicate standard error. 


\section{Discussion}

In this study, we examined: $N$. glauca tree density variation in flood and control plots; and between immediate flood, flood and sand dune zones. We also examined $N$. glauca soil-stored seed bank density and allelopathic impacts on L. sativa seed germination. $N$. glauca tree density varied across the plots and in relation to flooding zones. Larger numbers of $N$. glauca were found in the long-term flood zone than the short-term flood zone. No plants were recorded from areas not subject to flooding. Leachates obtained from dry leaves and twigs significantly decreased germination rate of $L$. sativa seeds whereas leachates obtained from fresh leaves and bark had no significant effect.

Weeds can cause detrimental effects on ecosystems by producing more seeds, occupying large productive areas, changing soil $\mathrm{pH}$ and hindering native flora by releasing allelopathic substances (Florentine, 1999). However, our study shows that density of $N$. glauca varied according to the disturbance. These differences between plots deserve special attention. Firstly, why were no N. glauca trees found in either the control fenced or unfenced plots? A possible explanation is, as has previously been reported, that $N$. glauca tends to colonize where there is high soil moisture and declines away from creeklines. The area around the new lake consists of well-drained sand with an open ground cover of Triodia scariosa ssp. scariosa and a sparse canopy of the Eucalyptus dumosa and E. oleosa. Secondly, why is $N$. glauca density nearly three times higher in the unfenced plots than fenced plots? The possible reason is grazing pressure from goats, kangaroos and rabbits. This high grazing pressure may have eliminated competition from native shrubs and grass species, creating ideal conditions for $N$. glauca seedlings to utilize available resources such as water and space to establish and survive during the subsequent summer months.

The variation in $N$. glauca density confirms that this species establishes in areas of high soil moisture. It is believed that the high rainfall event, resulting in flooding sufficient to leave standing water for several months, created ideal conditions for $N$. glauca establishment. Seeds of $N$. glauca are likely to have been brought from upstream and collected in the new lake. As flooded areas dried out, $N$. glauca seed deposited on peripheral mud (short-term flood zone) germinated and formed a dense stand. As Boyland et al. (1985) reported, N. glauca is a fast growing tree particularly after good rainfall events and produces flowers approximately one year after germination. $N$. glauca trees in the short-term flood zone may have supplied seeds to the long-term flood zone. This is supported by the population structure of $N$. glauca which shows that significant numbers of trees in the larger height and diameter class were found only in the short-term flood zone (Fig. 6).

The soil-stored seed bank of $N$. glauca reflects the density of stems present within respective plots and this was further confirmed by correlation analysis, showing a strong relationship. A patchy distribution of soil-stored seed is a common phenomenon for weed seeds. Although our study shows that a large quantity of seed is stored in the soil, the dynamics and longevity of small seed is unknown. From 
the methodology used here it cannot be said whether seeds germinated from the soil seed bank are transient (seeds germinate soon after they are shed) or persistent (seeds can remain dormant in the soil for several years (Thompson and Grime, 1979; Simpson et al., 1989)).

When using bioassays to examine the allelopathic effects on germination, it is prudent to examine different concentrations of leachates (Martin and Smith, 1994). None of the concentrations of fresh leaf and bark leachates had any impact on L. sativa seed germination. This may be a result of $N$. glauca leaves being covered with a thick wax layer preventing phenolic compounds oozing from leaves or that soaking for twenty-four hours may not be sufficient time for leaves and bark to release the compounds. In contrast, leachates obtained from dry leaves and twigs caused a significant $(p>0.001)$ reduction in germination of L. sativa seeds. As González et al. (1995) pointed out, allelopathic effects can be more pronounced during decomposition. However, extrapolation from controlled experiments to field conditions should be done with caution, since a number of biotic and abiotic factors may interact with each other in the field to influence the results (Florentine and Westbrooke, 2003). It is notable that $N$. glauca adds leaves and small twigs to the soil at the end of the dry season. Martin and Smith (1994) found a high proportion of phenolic or toxic compounds located in shallow $(\sim 5 \mathrm{~cm})$ soil where seeds tend to germinate. The accumulation of leaves and small twigs on the soil surface may release toxic substances after a small amount of rainfall, the time most native species germinate. Newly emerged radicles are very sensitive to allelochemicals (Florentine, 1999), and high concentrations can easily kill new recruits. Further, since this species tends to colonize along creek-lines, dry leaves and twigs can also be transported and deposited downstream, with detrimental effects on downstream vegetation. Dendrochronology confirms that $N$. glauca invaded Olary Creek, and adjacent mallee shrubland following the 1997 flood event. It appears likely that seeds travelled during the flood event and were deposited along the banks and further into surrounding shrublands.

\section{Conclusion}

N. glauca is potentially a serious weed in arid catchments such as Olary Creek. Our study suggests that this species has traits that are comparable with other arid zone weed species. N. glauca tree density is significantly higher in the control plots where grazing has eliminated competition from pre-existing shrub and grass species. Native species are already facing increased grazing pressure from native and exotic animals (Westbrooke et al., submitted) and drought. Invasion by weed species such as $N$. glauca may put further pressure on their survival. Further research is required, particularly on flowering and fruiting phenology, seed production and viability and impact of fire on soil-stored seedbank density. 


\section{Acknowledgements}

We thank Chantelle Solly and Benn Sheffield for help with data collection and Marion O'Keefe for field assistance and preparation of study site map (Fig. 1). The University of Ballarat provided financial support for this study.

\section{References}

Bertiller, M.B., 1996. Grazing effects on sustainable semiarid rangelands in Patagonia: the state and dynamics of the soil seed bank. Environmental Management 20, 123132.

Boyland, D.E., Carolin, R.C., George, A.S., Jessop, J.P., Maconochie, J.R. (Eds.) (1985). Flora of Central Australia. Reed Books, Sydney, 537pp.

Cellot, B., Mouillot, F., Henry, C.P., 1998. Flood drift and propagule bank of aquatic macrophytes in a riverine wetlands. Journal of Vegetation Science 9, 631640.

Cunningham, G.M., Mulham, W.E., Milthorpe, P.L., Leigh, J.H., 1981. Plants of Western New South Wales. N.S.W. Government Printing Office, Sydney.

Day, R.W., Quinn, G.P., 1989. Comparisons of treatments after an analysis of variance in ecology. Ecological Monographs 59, 133138.

Dietz, H., Winterhalter, P., 1996. Phytotoxic constituents from Bunian orientalis leaves. Phytochemistry 42, 10051010.

Evenari, M., Newman, G., 1952. The germination of lettuce seeds. The influence of fruit coat and endosperm upon germination. Bulletin of Research Council of Israel 2, 7578.

Florentine, S.K., 1999. Ecology of Eucalyptus victrix in the grassland in the floodplain of the Fortescue River. Ph.D. Thesis. Curtin University of Technology, Perth, 185pp.

Florentine, S.K., Westbrooke, M.E., 2003. Evaluation of allelopathic potential of the newly emerging weed Solanum mauritianum Scop. (Solanaceae) in wet tropics of north east Queensland. Plant Protection Quarterly 18, 2325.

Florentine, S.K., Craig, M., Westbrooke, M.E., 2003. Flowering, fruiting, germination and seed dispersal of the newly emerging weed Solanum mauritianum Scop. (Solanaceae) in the wet tropics of north Queensland. Plant Protection Quarterly 18, 116120.

González, L., Souto, X.C., Reigosa, M.J., 1995. Allelopathic effects of Acacia melanoxylon R. Br. phyllodes during their decomposition. Forest Ecology and Management 77, 5363.

Hughes, M.K., 1992. Dendroclimatic evidence from the western Himalaya. In: Bradely, R.S., Jones, P.D. (Eds.), Climate Since A.D. 1500. Routledge, London, New York, pp. 415431.

Martin, L.D., Smith, A.E., 1994. Allelopathic potential of some warm season grasses. Crop Protection 13, 388392.

Mizrachi, N., Levy, S., Goren, Z., 2000. Fatal poising from Nicotiana glauca leaves: identification of anabasine by gas chromatography/mass spectrometry. Journal of Forensic Science 45, 736741.

Panter, K.E., Weinzweig, J., Gardner, D.R., Stegelmeier, B.L., James, L.F., 2000. Comparison of cleft palate induction by Nicotiana glauca in goats and sheep. Teratology 61, 203210.

Simpson, R.L., Leck., M.A., Parker, V.T., 1989. Seed banks: general concepts and methodological issues. In: Leck, M.A., Parker, V.T., Simpson, R.L. (Eds.), Ecology of soil seed banks. Academic Press Inc., San Diego, pp. 38.

Sims, D.N., James, R., Christensen, T., 1999. Another death due to ingestion of Nicotiana glauca. Journal of Forensic Science 44, 447449.

Thompson, K., Grime, J.P., 1979. Seasonal variation in the seed banks of herbaceous species in ten contrasting habitats. Journal of Ecology 67, 893921.

Varnjic, J.A., Woods, M.J., Barnard, J., 2000. soil mediated effects on germination and seedling growth of coastal wattle (Acacia sophorae) by the environmental weed, bitou busy (Chrysanthemoides monilifera spp. Rotundata). Austral Ecology 25, 445453. 
Virtue, J.G., Groves, R.H., Panetta, F.D., 2001. Towards a system to determine the national significance of weeds in Australia. In: Virtue, J.G., Groves, R.H., Panetta, F.D. (Eds.), Weed Risk Assessment. CSIRO Publishing, Australia, pp. 212-214.

Westbrooke, M.E., 1999. Episodic events in the regeneration of Myoporum platycarpum ssp. platycarpum in south-eastern Australia. In: People and rangelands- Building the Future. Proceedings of the VIth International Rangeland Congress, Australia, pp. 212-214.

Westbrooke, M.E, Florentine, S.K., Milberg, P. Arid land vegetation dynamics after a rare flooding event: influence of fire and grazing. Journal of Arid Environments, submitted.

Weston, M., Westbrooke, M.E., 1999. The role of episodic events in moulding the vegetation of a part of western New South Wales, In: People and Rangelands-Building the Future, Proceedings of the VIth International Rangeland Congress, Australia, pp. 255-256.

Williams, J.A., West, C.J., 2000. The ecology and management of environmental weeds: foreword. Australian Journal of Ecology 25, 423-424. 